\title{
Conservative Management of Uterovesical Fistula Following Primary Caesarean Section
}

\author{
Bastakoti $\mathbf{R}^{1}$, Saha $\mathbf{R}^{2}$ \\ ${ }^{1}$ Rashmi Bastakoti, MD Resident; ${ }^{2}$ Rachana Saha, Associate Professor and Head; Department of Obstetrics and \\ Gynaecology, Kathmandu Medical College Teaching Hospital, Kathmandu, Nepal.
}

\section{ABSTRACT}

Uterovesical fistula is an abnormal communication between uterine cavity and the bladder. It is a rare type of fistula accounting for four percent of all cases of urogenital fistula. However the incidence of uterovesical fistula has been rising due to increasing incidence of lower segment caesarean section. Uterovesical fistula is seen more after repeated caesarean section rather than primary section. This is a case report of a primipara with uterovesical fistula following primary emergency Caesarean section on her 12th postoperative day for foetal distress. She was managed conservatively using IV antibiotics and catheterization for six weeks.

Key words: Caesarean section, Uterovesical fistula, Youssef's syndrome.

\section{INTRODUCTION}

Uterovesical fistula is an abnormal communication between uterine cavity and the bladder. It is a rare type of fistula accounting for only four percent of all cases of urogenital fistula ${ }^{1,2}$. However the incidence of uterovesical fistula has been rising due to increasing incidence of lower segment caesarean section ${ }^{3}$. Uterovesical fistula is seen more after repeated caesarean section rather than primary section ${ }^{4,5}$. Other cause of uterovesical fistula is uterine artery embolisation ${ }^{6}$. The development of fistula is believed to be related to higher attachment of bladder in relation to lower uterine segment, usually secondary to scarring from the previous surgery. With an unrecognised bladder injury or suture transfixation of bladder, a tract may develop between bladder and uterine wall.

Conservative treatment is indicated when the fistula is diagnosed early. Spontaneous healing is reported in five

\section{Address for correspondence}

Rashmi Bastakoti

MD Resident

Department of Obstetrics and Gynaecology

Kathmandu Medical College Teaching Hospital,

Kathmandu, Nepal.

E-mail: rashmibastakoti5@gmail.com percent of women 7 . Surgical treatment is indicated when conservative treatment has failed or in cases involving a large fistula. Small uterovesical fistula is managed conservatively whereas large fistula is managed surgically.

\section{CASE REPORT}

A 27 year primipara on her 12th postoperative day following emergency lower segment Caesarean section for foetal distress was admitted on 2012 February 28 to Kathmandu Medical College Teaching Hospital with complaints of oedema of both legs, pain at operation site, abdominal distension, foul smelling blood mixed vaginal discharge and fever. At time of admission she was conscious, cooperative, and had bilateral pedal oedema. After admission in the ward she was unable to pass urine so Foley's catheterization was done. Haemorrhagic urine was drained in urobag. Ultrasound scan was done on $15^{\text {th }}$ postpartum day in which uterus was poorly visualized, with gaseous bowel loops seen in lower abdomen, heteroechoic collection in pelvis suggestive of free air in peritoneal cavity (suggestive of uterovesical fistula). So Computerized Tomography (CT) scan was done on $16^{\text {th }}$ postpartum day which showed bulky uterus with fluid and air collection in endometrial cavity. A large defect in anterior wall of lower part of body of uterus with uterine cavity communicating with a large air and fluid filled loculated intraabdominal fluid collection anterior and 


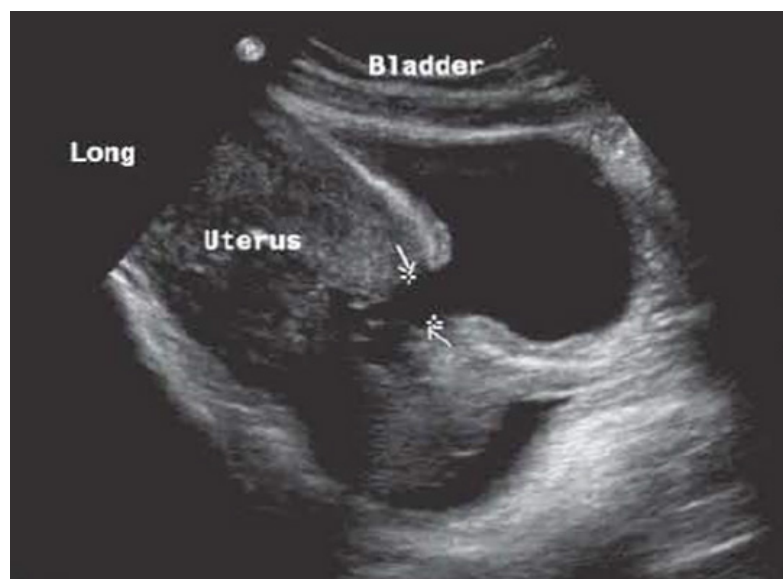

Figure 1: Ultrasound picture showing communication between uterus and urinary bladder.

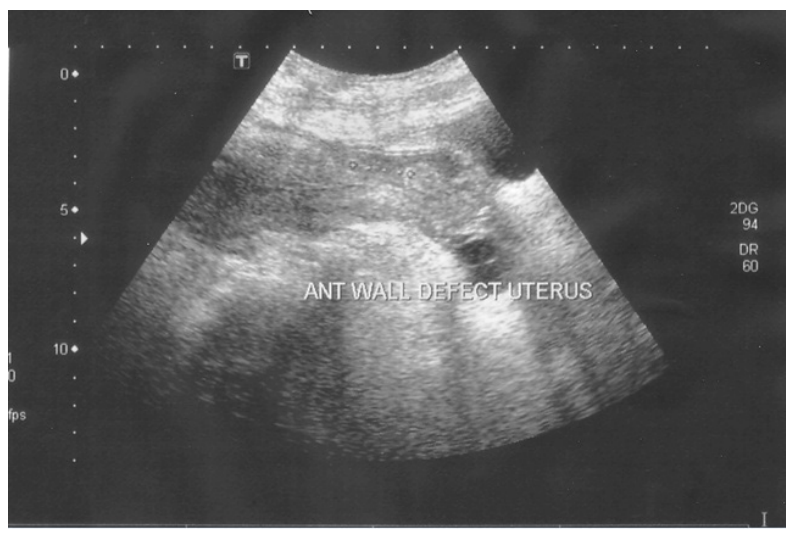

Figure 2: Ultrasound picture showing anterior wall defect in the uterus.

superior to uterus was noted. And another small defect in posterior wall of urinary bladder communicating with above described loculated intraabdominal fluid collection was also seen.

Her haemoglobin was $4.1 \mathrm{gm} \%$ so she received total five units of blood. After blood transfusion her haemoglobin reached to $10.9 \mathrm{gm} \%$. She was managed conservatively with six weeks catheterization, intravenous and oral antibiotics. Since her catheter was repeatedly blocked with flecks in urine, examination under anaesthesia was done and intracervical catheter was kept in situ. Patient was discharged on $15^{\text {th }}$ day of admission with both catheters in situ (Foleys catheter and intracervical catheter). She came in outpatient department after a week. Since there was only scanty drainage from intra cervical catheter, it was removed. Her Foleys catheter was changed after two weeks and removed after four weeks. Repeat ultrasound was done after fifty days which showed normal scan. After Urology consultation, cystoscopy was done on $51^{\text {st }}$ postoperative day, which showed intact bladder mucosa.

\section{DISCUSSION}

Nowadays uterovesical fistula is very rare because of improved obstetric practice. Most of them are associated with birth injury to or necrosis of the bladder wall directly over the dehiscence of a lower segment caesarean section scar ${ }^{8}$. When there is inadequate mobilization of bladder inferiorly or laterally it may be injured during delivery of a large foetal head or it may be accidentally included in the suture used to close the uterine incision. Fistula forms when sutures are absorbed 9 . A woman may experience involuntary loss of urine or she may remain continent. She may complain of cyclical haematuria and amenorrhoea. This symptom is called menouria of Youssef ${ }^{10}$. Józwik and Józwik ${ }^{11}$ have proposed a classification for uterovesical fistula which is based on the route of menstrual flow ${ }^{11}$.

Type 1 (Youssef syndrome) is menouria, amenorrhoea, and complete continence of urine.

Type 2 is dual direction menstrual flow via bladder and vagina.

Type 3 is normal vaginal menses but lack of menouria.

Vaginal examination fails to reveal a fistula though occasionally trickling of urine is seen through cervical os. Cystoscopy, cystogram and/or hysterogram are useful in diagnosis. The vesical orifice of the fistula is always supratrigonal when viewed through the cystoscope ${ }^{12}$. Management options include conservative and surgical management. Conservative management is indicated when the fistula is diagnosed early and is small. Spontaneous healing is reported in five percent of women. Surgical treatment is indicated when conservative treatment has failed or in cases involving a large fistula. This is either through laparoscopy or laparotomy immediately after the diagnosis (within 48 hours) or four months after diagnosis. The pregnancy rate after repair has been reported to be $31.25-37.5 \%$ with a rate of term deliveries of $25 \%$.

Our case was managed conservatively and absence of fistula was confirmed by cystoscope. Conservative management was best for small uterovesical fistula to avoid surgical complications. 


\section{CONCLUSION}

Conservative management is recommended with expectation of spontaneous closure in small fistula.
Prolonged use of self retaining bladder catheter is helpful in such cases.

\section{REFERENCES}

1. Kilinic F, Bagis T. Unusal case of post-caesarean vesicouterine fistula (Youssef's Syndrome). Int $\mathrm{J}$ Urol. 2003;10:235-8.

2. Park QR, Kim TS. Sonographic diagnosis of vesicouterine fistula. Ultrasound Obstet Gynaecol. 2003;22:82-4.

3. Tancer ML. Vesicouterine Fistula -A review. Obstet Gynecol Surv. 1986;41:743-53.

4. Jozwik-M, Jozwick M, Lotocki W. Vesicouterine fistula -an analysis of 24 cases from Poland. Int J Gynecol Obstet. 1997;5792:169-72.

5. Hadzi-Djokiej B, Pejcic TP, Colovicv C. Vesicouterine fistula: report of 14 cases. BJU Int. 2007;100:1361-3.

6. Sultana CJ, Aizenman L, Chon JK. Vesicouterine fistula after uterine artery embolisation: a case report. Am J Obstet Gynecol. 2002;187:1726-27.
7. Porcaro AB, Zicari M. Vesicouterine fistula following caesarean section. Int J Urol Nephrol. 2003:33544.

8. Yip SK, Leung TY. Vesicouterine fistula: an updated review. Int Urogynecol J Pelvic Floor Dysfunct. 1998;9:252-6.

9. Issa MM, Schmid HP, Stamey TA. Youssef's syndrome: Preservation of uterine function with subsequent successful pregnancy following surgical repair. Urol Int. 1994;52:220-2.

10. Jozwik M, Jozwik M. Clinical classification of vesicouterine fistula. Int $J$ Gynecol. 2000;70(30):353-7.

11. Youssef AF. Menouria following lower segment caesarean section. Am J Obstet Gynecol. 1957;73:759.

12. Lenkovsky Z, Pode D, Shapiro A, Caine M. Vesicouterine fistula: a rare complication of cesarean section. J Urol. 1988;139:123-5. 